\title{
Prevalence of periodontal disease among mine workers of Zonguldak, Kozlu District, Turkey: a cross-sectional study
}

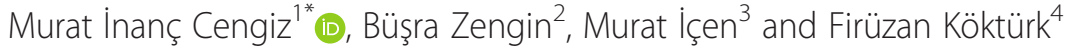

\begin{abstract}
Background: Occupational injuries cause major health problems in all nations. Coal mining is one of the largest, oldest industries in the world. However, there is relatively little available literature concerning the health status of coal miners. The purpose of this work is to assess the prevalence of periodontal disease among coal miners and provide a basis for planning and evaluating the data from community oral health services.
\end{abstract}

Methods: A cross-sectional study was conducted 106 men selected based on a stratified cluster sampling procedure. The study was performed among the mine workers of Zonguldak, Kozlu District, Turkey. The questionnaire prepared by the American Academy of Periodontology risk assessment test was used for the evaluation. The data were collected byWorld Health Organization (WHO) oral health assessment form, and clinical examination was conducted by the method recommended by the WHO oral health surveys. Statistical analysis was performed using SPSS software programme.

Results: The overall prevalence of periodontal disease was found to be $96.2 \%$ and was determined by considering subjects with Community Periodontal Index scores of 1-4 as diseased and the healthy subjects comprised of a mere 3.8\%. Furthermore, various disturbing or embarrassing work conditions were reported. Statistically significant differences were observed among the workers who brush their teeth daily and visit dental attendance within the last two years have better periodontal status than those of the others $(p<0.05)$.

Conclusions: The present level of periodontal disease in coal mine workers is severe. Moreover, its distribution and severity are strongly influenced by host susceptibility and risk factors. The priority should be based on population strategy and primary prevention programmes to benefit the periodontal health by promoting self-care and oral hygiene.

Keywords: Coal mining, Occupational health, Periodontal diseases

\section{Background}

Individuals can develop diseases in association with genetic factors and environmental exposure. Increasing industrial activity around the world has improved people's standards of living, but these increased activities have also led to various occupational hazards [1]. This situation affects people's general and oral health due to their exposure to dangerous occupational environments $[2,3]$. The effects of the aetiological agents responsible for the oral findings concerning occupational diseases

\footnotetext{
* Correspondence: micengiz79@yahoo.co.uk

'Department of Periodontology, Faculty of Dentistry, Bülent Ecevit University, 67600 Kozlu, Zonguldak, Turkey

Full list of author information is available at the end of the article
}

depend on the physical, chemical, and bacterial characteristics of these agents and their entrance ways into the body.

Oral health is an integral part of general health. The oral cavity establishes a connection between the environment and the body, creating a region that is prone to occupational diseases because it is directly exposed to various occupational pollutants. Oral disorders are directly related to people's general health status. Occupational diseases that occur in the mining, metalwork, and chemical industries can also affect the periodontium and oral mucosa $[2,3]$.

Trends in periodontal diseases have seen rapid changes throughout the world [3, 4]. Periodontitis is one 
of the most widespread chronic diseases at a global scale. Due to an increase in tobacco use, periodontal diseases are one of the major challenges faced by countries such as Turkey. The role of personal risk factors, such as poor lifestyle and negative psychosocial conditions, has been said to play an important role in the aetiology of adult periodontitis [5]. Previous epidemiological studies on the prevalence and severity of periodontal disease have reported that periodontal health is worse in the developing countries than it is in the industrialized ones. The researchers found that the metal [6], metalwork $[7,8]$ and chemical industries $[8,9]$ can affect periodontal disease patterns, but no specific pattern was observed in our study, and the pattern of periodontal disease in mine labourers was comparable to that of the general population.

Coal mining is one of the oldest branches of industry in both Turkey and the rest of the world $[3,10,11]$. The Zonguldak coal mining industry comprises many miners [11]. Tens of thousands of miners work for the National Hard Coal Enterprises (TTK), and private-sector businesses were legally commissioned in 2000; approximately 3000 miners are known to be illegal. In Turkey, the TTK Labour Security Officer is responsible for the implementation and distribution of information on security laws concerning the regulation of coal mines.

Because of the exhausting physical nature of the coal mining business, female miners were not seen in the study population. Workers' exposure to coal dust and other types of particulate matter make them more prone to systemic diseases than the general population is. Coal mining production occurs throughout the week; the workers are engaged in tedious work around the clock, working in three rotating shifts of $8 \mathrm{~h}$ each. The physically tedious work drives people to consume alcohol and tobacco [12]. These substances may lead to the deterioration of their oral health in terms of periodontal and oral mucosal disease [13, 14]. Moreover, because of its disruption of the regular circadian rhythm activity in the body, shift work may lead to several dangerous health conditions $[3,11,15]$.

The work environment is a major factor for health determinants, especially considering that oral health is crucial to the general health and well-being of individuals [16-18]. There are many studies about the oral health status of workers in different sectors. Among Indian workers in coal mines, $55.6 \%$ had caries experience [17], and in the industrial sector, the occurrence of dental caries was $46.5 \%$ [16]. Another study with Brazilian workers in a textile industry showed that orofacial pain had a significant impact on the performance of labour activities (28.5\%), with tooth ache affecting $25 \%$ of individuals and generating absenteeism in $11.6 \%$ of workers [19]. Cavalcanti et al. found a high index of decayed-missing- filling (DMFT) in a study of the oral health status of Brazilian textile industry workers [20]. A cross-sectional study of white-collar port workers in India found thatoral health had an impact on the quality of life of workers, but periodontal disease, though prevalent amongst the participants, had no significant impact on their daily activities [21]. Only one paper has been published so far concerning the oral health status of underground coal mine workers [3]. Thus, the purpose of the present study was to assess the prevalence of periodontal disease among these workers. A further objective was to use the data to provide a baseline for planning and evaluating the oral health status of miners working in this field.

\section{Methods}

A cross-sectional study was carried out to assess the periodontal disease status of underground coal mine workers in Zonguldak, Turkey, coal mines. Zonguldak is located in the Western Black Sea region and is the oldest mine in Turkey. A total of 106 subjects were included in this cross-sectional study. The questionnaire prepared by the American Academy of Periodontology (AAP) was employed. It included questions about sociodemographic factors, oral health knowledge, and periodontal and systemic health. All underground coal mine workers were asked to complete the survey. According to the scores, the study population was classified into groups with low, medium and high risk for periodontal diseases. The AAP risk assessment test was used to evaluate this risk [22]. The questionnaire items covered the following topics, which were considered in the data analysis: age, frequency of dental attendance, tooth brushing and flossing frequency, presence of gum recession, tooth extraction history, presence of gum diseases, and smoking habits.

The study population comprised 106 men aged 1752 years, with a mean age of $32 \pm 2$ years, who were interested in having a periodontal examination. The study group was made up of workers who satisfied the inclusion and exclusion criteria. The inclusion criterion was that workers were present on the day of examination. The exclusion criteria were as follows: (1) individuals suffering from any systemic illness, (2) individuals who were not willing to participate in the study, and (3) individuals with a habit of bruxism. Ethical clearance was obtained from the Bulent Ecevit University Ethical Committee. Permission was obtained from the mine association and owners of the coal mine.

The study population comprised 106 men aged 1752 years; the sample was divided into age groups of $17-$ 36 years and 37-52 years. Education level was categorized into two groups: primary school only and more than primary school. Information on the frequency of daily tooth brushing was collected using the following 
question: "How many times did you brush your teeth yesterday?" (times/day). Participants were also asked whether they had visited a dental clinic for a regular check-up in the year prior to the interview (yes or no).

Smoking status was divided into two categories: nonsmokers and current smokers. Current smokers were defined as those who smoked 1 pack per day. Obesity was measured based on a standardized physical examination. The participants self-reported weight and height, and we calculated body mass index (BMI) according to the standard formula. Weight was categorized as non-obese or obese using BMI $30\left(\mathrm{~kg} / \mathrm{m}^{2}\right)$ as a cut-off-value, and underweight was classified as BMI $<18.5 \mathrm{~kg} / \mathrm{m}^{2}$. Fasting plasma glucose and white blood cell (WBC) counts were measured, and chest X-rays were obtained.

All mine workers in the selected study group were informed about the survey prior to the survey date, and all workers who were present on the days of the survey were included in the study. Special permission was obtained from the coal mine owners' association authorities for the miners to participate. An intraoral examination was performed in natural sunlight, and an additional light source was used when necessary. Oral examination was carried out using mouth mirrors and community periodontal index (CPI) probes, as recommended by the World Health Organization (WHO) [23]. A type 1 intraoral examination was performed by a single examiner assisted by two dental assistants. To reduce inter-examiner variability and enhance agreement, the examiners were trained prior to the study at Bülent Ecevit University's Faculty of Dentistry by an expert examiner (MIC, Associate Professor in Faculty of Dentistry, Department of Periodontology). The weighted kappa statistic was $90 \%$. Periodontal status was recorded using five possible scores: 0 , healthy; 1 , bleeding on probing; 2, calculus; 3 , shallow periodontal pockets; and 4, deep periodontal pockets [24].

The recorded data were analysed using the Statistical Package for the Social Sciences (SPSS; SPSS Inc., Chicago, IL, USA) software, version 19. Descriptive statistics included computation of frequency and percentages. The statistical test applied for the analysis was the chisquare test. For all tests, the confidence level and level of significance were set at $95 \%$ and $5 \%$, respectively.

\section{Results}

Table 1 describes the general profile of the study population. All the workers were male and insured. They were all rotating-shift workers. The majority of workers belonged to the youngest age group (17-36 years), and only 7 workers belonged to the oldest age group (> 47 years). All the workers had very low incomes (less than $\$ 450$ per month). Dietary intake of total calories was low. They were all underweight to normal weight $\left(18.5\right.$ to $\left.26 \mathrm{~kg} / \mathrm{m}^{2}\right)$.
Table 1 Demographic data, oral hygienepractices, tobacco and education

\begin{tabular}{|c|c|c|c|}
\hline Variables & Levels & No.of subjects & Percentage \\
\hline \multirow[t]{2}{*}{ Age } & $17-36$ years & 84 & 79.2 \\
\hline & $37-52$ & 22 & 20.8 \\
\hline \multicolumn{4}{|l|}{ Education } \\
\hline Primary school & $1-5$ years & 30 & 28.3 \\
\hline Middle school & $6-8$ years & 26 & 24.5 \\
\hline High school & 9-11 years & 50 & 47.2 \\
\hline \multirow[t]{2}{*}{ Years of working } & $1-5$ yeras & 57 & 53.8 \\
\hline & $6-18$ years & 49 & 46.2 \\
\hline \multirow[t]{2}{*}{ Oral hygiene aid } & Finger & 79 & 74.5 \\
\hline & Toothbrush & 27 & 25.5 \\
\hline \multirow[t]{2}{*}{ Tooth brush frequency } & once a day & 27 & 25.5 \\
\hline & 23 times/week & 79 & 74.5 \\
\hline \multirow[t]{3}{*}{ Using material } & None & 37 & 35 \\
\hline & Water & 42 & 40 \\
\hline & Toothpaste & 27 & 25 \\
\hline \multirow[t]{2}{*}{ Tobacco habits } & Non-smokers & 44 & 41.5 \\
\hline & $\begin{array}{l}\text { currentsmokers } \\
\text { (1 pack/day) }\end{array}$ & 62 & 58.5 \\
\hline Alcohol habits & None & - & - \\
\hline Working shift pattern & Rotating & 106 & 100 \\
\hline \multirow{2}{*}{$\begin{array}{l}\text { Frequency of dental } \\
\text { attendance within the } \\
\text { last two years }\end{array}$} & yes & 40 & 37.7 \\
\hline & no & 66 & 62.3 \\
\hline
\end{tabular}

Most workers had had eight years of schooling. More than half were unskilled workers. A total of $58.5 \%$ of the workers had the habit of smoking (current smokers: 1 pack/day). They were not heavy smokers. The rest, only 44. (41.5\%) workers, were non-smokers. Alcohol and chewing tobacco were not used by the workers.

Nobody had visited any dental service or a dentist regularly. Only a minority of the workers had visited a dentist in emergency conditions. While $74.5 \%$ of the workers claimed to brush their teeth 2-3 times a week, only $25.5 \%$ reported daily tooth brushing. Most workers used only water and their fingers for cleaning their teeth. Only four workers claimed to have teeth in good condition, while the great majority of the workers declared that their teeth were bad. Healthy gingival conditions were reported by only four workers. Most of the workers reported that they were in need of dental treatment. A majority of the workers claimed to have had a great deal of trouble in their lifetime with their teeth or gums, and these problems were related to the work environment. Various disturbing or embarrassing work conditions were reported frequently (Table 2 ). The results for the questions on function of the masticatory system are 
Table 2 Percentage of workers who reported having been exposed to various work conditions $(n=106)^{*}$

\begin{tabular}{ll}
\hline Work condition & Percentage \\
\hline Temperature excessively warm & 10 \\
Temperature excessively cold & 12 \\
Excessive changes in temperature & 21 \\
Draft & 15 \\
Humidity & 35 \\
Dirtiness & 45 \\
Dust & 72 \\
Unpleasant smell & 20 \\
Smoke & 15 \\
Mess and litter & 30 \\
Stress from the lifting of heavy weights & 60 \\
Vibration & 40 \\
High noise level & 45 \\
\hline
\end{tabular}

"More than one selection

shown in Table 3. The majority of the workers reported using analgesics for headache or facial pain daily or weekly.

Table 4 shows the characteristics of the subjects by periodontal status. The overall prevalence of periodontal disease (CPI score 1-4) was $96.2 \%$, and only 4 (3.8\%) were classified as healthy (CPI score 0 ). In the largest age group (17 to 36 years), CPI scores 1 to 2 were most common (90.4\%) and least common in the 37- to 52year-old group (81.8\%). CPI scores of 3 to 4 were most common in the 37-52-year-old group (18.2\%) and least common in the 17 - to 36 -year-old group (4.8\%). The healthy subjects, a mere $4.8 \%$ of the participants, were all in the 17- to 36-year-old group; there were no healthy subjects in other age groups. These findings were numerically important but not statistically significant $(p>0.05)$. Furthermore, no statistically significant differences were found between educational levels ( 1 to 8 and

Table 3 Percentage of respondents with (daily) masticatory system symptoms $(n=106)$

\begin{tabular}{lll}
\hline Symptom & $n=106$ & Percentage of subjecs \\
\hline Pain & 2 & 1.8 \\
Clicking or grating in jaw joint & 3 & 2.8 \\
Tenderness of teeth & 27 & 25.8 \\
Tenderness/ fatigue in cheeks & 2 & 1.8 \\
Difficulties in opening mouth & 2 & 1.8 \\
Tooth mobility & 11 & 10.4 \\
Bleeding while brushing & 36 & 35.2 \\
Grinding of teeth & 5 & 4.7 \\
Locking of jaw & - & - \\
Tooth recession & 18 & 17.1 \\
\hline
\end{tabular}

9 to 11 years), years of working or smoking habit and periodontal CPI score $(p>0.05)$. The only statistically significant differences we found were that the workers who brushed their teeth daily and visited dental offices within the last two years had better periodontal status than the others $(p<0.05)$.

\section{Discussion}

People's standard of living has been enhanced by the expansion of industrial activity; however, industrial production has also caused many occupational hazards. Developments in technology have made professions easier in many ways, but at the same time, these developments have brought new occupational hazards $[1,3]$. Although coal mining is one of the oldest industries in the world [2,3], little research has been carried out on how it affects coal miners' health. This study sought to address this gap by considering periodontal disease in a Turkish population of underground coal miners. The study area for this research is a rural area where most people belong to the lower socioeconomic class and have low educational status. The workers in the mines work for at least $10 \mathrm{~h}$ per day to earn 1300-1800 Turkish lira (less than \$450) per month. They work in deep, open pits where the air is thick with dust from dry drilling. Unfortunately, there is insufficient safety equipment to protect workers from occupational injury; for this reason, the coal mines are also called "death pits". It is estimated that half the mine workers are exposed to this dust continuously, and they develop various pulmonary diseases due to the absence of respiratory masks. Workers' living conditions are at a substandard level.

There is not much information available on the occupational general and oral health status of mine workers. Due to this lack research, in the context of oral health, it is difficult to compile and compare the data obtained from different studies in comparable groups. In this research, the oral health of underground workers in Zonguldak, Turkey, was evaluated by performing a cross-sectional study. In the literature, only one study has focused on coal miners [3]. In the present study, the workers were in the age range of 17 to 52 years. Our study subjects were younger than those of Abbas et al. and comparable in age to those of Kumar et al., Solanki et al., and Duraiswamy et al. [3, 8, 24, 25]. In addition, in this study, most subjects had 8 years of schooling, and the rest had 11 years of schooling. Our findings were comparable to those of Kumar et al. and Solanki et al., but they contrasted with Abbas et al.'s results, where $49.7 \%$ of the participants were uneducated [3, 8, 24].

In this study, in accordance with the literature, it was determined that the oral hygiene of miners is not good. Only $25.5 \%$ of the workers reported daily tooth brushing. Only four (3.8\%) workers claimed to have teeth in good 
Table 4 Characteristics of subjects by periodontal status

\begin{tabular}{|c|c|c|c|c|c|c|}
\hline & Variables & Health & Scores 1-2 & Scores3-4 & $\times 2$ & P-Volve \\
\hline \multirow[t]{2}{*}{ Age } & $17-36$ years $(n=84)$ & $4(4.8 \%)$ & 76 (90.4\%) & $4(4.8 \%)$ & 5.4 & $P>0.05$ \\
\hline & $37-52$ years $(n=22)$ & - & 18(81.8\%) & $4(18.2)$ & & \\
\hline \multirow[t]{2}{*}{ Education } & 1 to 8 years $(n=56)$ & $1(1.8 \%)$ & $50(88.3 \%)$ & $5(8.9 \%)$ & 1.5 & $P>0.05$ \\
\hline & $9-11$ years $(n=50)$ & $3(6 \%)$ & $44(88 \%)$ & $3(6 \%)$ & & \\
\hline \multirow[t]{2}{*}{ Years of working } & 1 to 5 years $(n=57)$ & $4(7 \%)$ & $50(87.7 \%)$ & $3(5.3 \%)$ & 4.3 & $P>0.05$ \\
\hline & 6-to 18 years $(n=49)$ & & 44(89.8\%) & $5(10.2 \%)$ & & \\
\hline \multirow[t]{2}{*}{ Tooth brush } & daily $(n=27)$ & $4(14.8 \%)$ & $21(77.8)$ & $2(7.4)$ & 12.2 & $P<0.05$ \\
\hline & 2-3/ weeks(79) & - & 73(92.4\%) & $6(7.6 \%)$ & & \\
\hline \multirow[t]{2}{*}{ Smoking } & Non smoker $(n=44)$ & $4(9.1 \%)$ & 37(84.1\%) & $3(6.8)$ & 5.8 & $P>0.05$ \\
\hline & Smoker $n=62$ & & 57(91.9) & $5(8.1 \%)$ & & \\
\hline \multirow{2}{*}{$\begin{array}{l}\text { Frequency of dental attendance } \\
\text { within the last two years }\end{array}$} & yes $(n=40)$ & $4(10 \%)$ & $34(85 \%)$ & $2(5 \%)$ & 7.2 & $P<0.05$ \\
\hline & no(66) & - & 60(90.9\%) & $6(9.1)$ & & \\
\hline Total & $(n=106)$ & $4(3.8 \%)$ & $94(88.7 \%)$ & $8(7.5 \%)$ & & \\
\hline
\end{tabular}

condition, while the overwhelming majority declared that their teeth were bad. Most workers claimed to have had extensive trouble with their teeth or gums in their lifetimes, and these problems were related to the work environment. Our findings concerning tooth brushing frequency are comparable to those in the literature $[8,24,25]$. However, contrary to the findings of Abbas et al., $63.2 \%$ of our participants reported using toothbrushes and toothpaste to clean their teeth daily [3]. In the present study, the workers were tobacco users $(58.5 \%)$, although they were not heavy smokers (1 pack/day). Only 44 (41.5\%) did not use tobacco in any form, and none of the workers used chewing tobacco or alcohol. The results concerning tobacco use are comparable to those of the literature [2, 3, 7, 8, 24-26], but the lack of alcohol usage contrasted with most findings in the literature. This may have been because alcohol was forbidden in the mine and is expensive.

Various disturbing work conditions were frequently reported. Oral diseases not only cause pain but severely impair many individuals and can affect various aspects of life, including oral functions, appearance and interpersonal relationships [21]. Most workers claimed to have had a great deal of trouble in their lifetime with their teeth or gums, and these problems were related to the work environment. Most workers reported using various analgesic medications to treat headache or facial pain daily or weekly. Furthermore, $35.2 \%$ of the coal workers experienced bleeding while brushing their teeth, 10.4\% had tooth mobility, and $17.1 \%$ had tooth recession. Our investigation showed that coal workers had rather poor dental conditions. However, this finding was explained by their irregular dental care habits, since none of the participants had been treated by dental services or made regular visits to the dentist in their adult lives. The survey also showed that most coal workers were aware of their poor dental health status, and many related their dental problems to the work environment. Poor work conditions, including exposure to dust, were reported. Grinding and clenching of teeth due to hyperactivity in the masticatory muscles is considered necessary for the development of pathological attention. The findings concerning self-reported disorders of the masticatory system were supported by clinical observations. To the best of our knowledge, no previous study can be compared with this part of our research; the results for the coal mine worker population are shown in Tables 2 and 3.

Mining workers' oral hygiene was extremely poor. A minority (25.5\%) of the workers used a toothbrush and toothpaste to clean their teeth. This poor oral hygiene of the workers also affected their periodontal condition in terms of the CPI, gingival bleeding, and/or periodontal pockets. Healthy gingiva was observed in only $3.8 \%$ of the workers. The overall prevalence of periodontal disease was $96.2 \%$ (88,7\% gingivitis and $7.5 \%$ periodontitis). This was determined by considering subjects with CPI scores of 1-4 as diseased and those with a score of 0 as healthy. All these findings were comparable to those of Abbas et al., Kumar et al., and Salonki et al., in which $94.4 \%, 98.25 \%$, and $95.1 \%$ of subjects had an unhealthy periodontium, with healthy gingivae only observed in $5.6 \%, 1.75 \%$, and $4.9 \%$ of subjects, respectively [3, 8, 24]. The low prevalence of periodontitis and the harshness of the working conditions may because the population was skewed towards a younger age.

No statistically significant differences were observed between age groups, educational levels (1-8 and 911 years), years of working, or smoking habits and periodontal CPI scores. Some differences between groups were numerically important, but not statistically significant $(p>0.05)$. These findings may have been due to the 
small sample size and the similarity of the variables to each other. Differences were observed between the workers who brushed their teeth daily and had visited dental offices within the last two years (who had better periodontal status) and the others $(p<0.05)$.

There is limited information regarding occupational estimates concerning oral health. In the present study, the prevalence of periodontal disease was found to be high among coal mine workers. However, we are aware of some possible methodological limitations: This study was conducted in only one mine in one city, and the sample size was small. Because this was a cross-sectional study, no cause-and-effect associations could be made. Nevertheless, we think that this research will lead to future studies with broader populations. More research should be carried out with a larger sample size to better characterize the oral problems faced by mine workers.

\section{Conclusions}

In the present study, the prevalence of periodontal disease was high in coal mine workers. Preventive medical and dental services should be provided for this urgent-need group through the establishment of community health centres. Effective oral health education and promotion workshops should be organized for underground mine workers. The workshops should be aimed at changing the perception that oral health is disparate to general health, and emphasis should be placed on the importance of oral health and its relationship to general health.

\section{Abbreviations}

AAP: American academy of periodontology; BMl: Body mass index; CPI: Community periodontal index; TTK: National hard coal enterprise; WBC: White blood cell; WHO: World Health Organization

\section{Acknowledgements}

Not applicable.

\section{Funding}

This work was supported by Bülent Ecevit University Research Foundation in Zonguldak (project no.2012/ 21-00-03)

\section{Availability of data and materials}

The raw data are available from the corresponding author for anyone who wishes to collaborate with us.

\section{Authors' contributions}

MiC and BZ made substantial contributions to the study conception and design. BZ, Mi, and FK made substantial contributions to data acquisition and interpretation. MiC, BZ, Mi, and FK were involved in drafting the manuscript and gave final approval of the version to be published.

\section{Ethics approval and consent to participate}

Ethics approval was received from the Ethical Committee for Research, Bülent Ecevit University. A written informed consent was obtained from all participants.

\section{Consent for publication}

Not applicable.

\section{Competing interests}

The authors declare that they have no competing interests.

\section{Publisher's Note}

Springer Nature remains neutral with regard to jurisdictional claims in published maps and institutional affiliations.

\section{Author details}

'Department of Periodontology, Faculty of Dentistry, Bülent Ecevit University, 67600 Kozlu, Zonguldak, Turkey. ${ }^{2}$ Department of Endodontics, Faculty of Dentistry, Kocaeli University, Kocaeli, Turkey. ${ }^{3}$ Department of Dentofacial Radiology, Faculty of Dentistry, Bülent Ecevit University, Zonguldak, Turkey. ${ }^{4}$ Department of Biostatistics, Faculty of Medicine, Bülent Ecevit University, Zonguldak, Turkey.

Received: 13 November 2017 Accepted: 13 March 2018

Published online: 16 March 2018

References

1. Subramanian A, Prakasom T. Epidemiology and management of diabetes mellitus in rural population of Kanyakumari district. Int JAPSBMS. 2013;2: 202-9.

2. Petersen PE, Hunmar P. Oral conditions among workers in the Danish granite industry. Scand J Work Environ Health. 1988;14:328-31.

3. Abbas I, Mohammad SA, Avidapu R. Oral health status of underground coal workers of Ramakrishnapur, Adilabad District, Telangana, India - acrosssectional study. J ClinDiagn Res. 2016;10:ZC28-31.

4. Peterson PE. Continuous improvement of oral health in the 21 st centurythe approach of the WHO Global Oral Health Programme. The World Oral Health Report 2003. WHO/NMH/NPH/ORH/03.2

5. Clarke NG, Hirsch RS. Periodontal risk factors for generalized periodontitis. J ClinPeriodontol. 1995;22:136-45.

6. Knychalska-Karwan Z, Biedowa J, Gawrzewska B, Kaczmarczyk-Stachowska A, Laskowska L, Pelc M, Szafraniec I, Wedler A. Dentition of workers of the salt mines in Wieliczka. CzasStomatol. 1973;26:1291-5.

7. Buda M, Sinho I, Mikalka S. Correlation between the chemical composition of the silicogenic dust from the atmosphere of nonferrous mines and the composition of the dental calculus of miners. Stomatologia (Bucur). 1972;19:289-95.

8. Kumar S. DagliRJ, Chandrakant D, Prabu D, Suhas K. Periodontal status of green marble mine labourers in Kesariyaji, Rajasthan, India. Oral Health Prev Dent. 2008;6:217-21.

9. Florescu M. Dental lesion in workers from sulphuric acid industry. Stomotologia (Bucur). 1972;19:395-403.

10. Government of India Ministry of Mines. Annual Report 2012-13.

11. Küçüker H. Occupational fatalities among coal mine workers in Zonguldak Turkey, 1994-2003. Occup Med (Lond). 2006;56:144-6.

12. Siegrist J, Rödel A. Work stress and health risk behavior. Scand J Work Environ Health. 2006;32:473-81.

13. Grover Harpreet S, Bharadwaj A, Singh Y. Smoking and periodontal disease. J Pharm Scilnnov. 2013;2:7-13.

14. Tezal M, Grossi SG, Ho AW, Genco RJ. Alcohol consumption and periodontal disease. The third National Health and nutrition examination survey. J Clin Periodontol. 2004;31:484-8.

15. Knutsson A. Health disorders of shift workers. Occup Med (Lond). 2003;53: $103-8$.

16. Singh $M$, Ingle NA, Kaur N, Yadav $P$, Ingle E, Charania Z. Dental caries status and oral hygiene practices of lock factory workers in Aligarh City. J Int Oral Health. 2015;7(6):57-60.

17. Abbas I, Mohammad SA, Peddireddy PR, Mocherla M, Koppula YR, Avidapu R. Oral health status of underground coal mine workers of Ramakrishnapur, Adilabad District, Telangana, India - a cross-sectional study. J Clin Diagn Res. 2016;10(1):28-31.

18. Gambhir RS, Sogi GM, Veeresha KL, Sohi RK, Randhawa A, Kakar H. Dental health status and treatment needs of transport workers of a northern Indian city: a cross-sectional study. J Nat Sci Biol Med. 2013;4(2):451-6.

19. Lacerda JT, Ribeiro JD, Ribeiro DM, Traebert J. Prevalence of orofacial pain and its impact on the oral health-related quality of life of textile industries workers of Laguna, SC. Brazil Ciênc Saúde Coletiva. 2011;16(10):4275-82.

20. Cavalcanti AFC, Fernandes LHF, Cardoso AMR, Santos JSJ, Maia EG, Cavalcanti AL. Oral health status of Brazilian workers of a textile industry. Pesq Bras Odontoped Clin Integr. 2017;17(1):e3454

21. Chowdary SM, Sudhir KM, Reddy VC, Kumar RWSK, Srinivasulu G. Oral impacts on daily performances in white-collar port workers in Nellore, Indiaa cross-sectional study. Int Marit Health. 2016;67(4):205-13. 
22. Park K. Text book of preventive and socialmedicine. 17th ed. Jabolpur: Banarasidas Bhanot; 2002. p. 632-3.

23. WHO Expert Group on Equipment and Materials for Oral Care (EGEMOC) The periodontal probe for use with the Community Periodontal Index of Treatment Needs. Oral Health Surveys-Basic Methods 5 th edition. World Health Organization. 2013;(19):47.

24. Solanki J, Gupta S, Chand S. Oral health of stone mine workers of jodhpur city, Rajasthan. India Saf Health Work. 2014;5:136-9.

25. Duraiswamy P, Kumar S, Daglı RJ, Chandrakont D, Kulkarnı S. Dental caries experience and treatment needs of green marble mine laborers in Udaipur District, Rajasthan. India J Dent Res. 2008;19:331-4.

26. Singh A, Purohit BM, Masih N, Kahndelwal P. Risk factors for oral diseases among workers with and without dental insurance in a national social security scheme in India. Int Dent J. 2014;64:89-95.

Submit your next manuscript to BioMed Central and we will help you at every step:

- We accept pre-submission inquiries

- Our selector tool helps you to find the most relevant journal

- We provide round the clock customer support

- Convenient online submission

- Thorough peer review

- Inclusion in PubMed and all major indexing services

- Maximum visibility for your research

Submit your manuscript at www.biomedcentral.com/submit
Biomed Central 